\title{
Nonenzymatic Electrochemical Sensor Based on PdAu Nanoflowers for the Detection of Hydrogen Peroxide
}

\author{
Xia Hu, Guangyu Shen* \\ Hunan Province Cooperative Innovation Center for The Construction \& Development of Dongting \\ Lake Ecological Economic Zone, College of Chemistry and Material Engineering, \\ Hunan University of Arts and Science, Changde, 415000, PR China \\ *E-mail: sgyrab@163.com
}

doi: $10.20964 / 2019.05 .26$

Received: 4 January 2019 / Accepted: 19 February 2019 / Published: 10 April 2019

\begin{abstract}
In this work, PdAu nanoflowers was synthesized and used to fabricate hydrogen peroxide sensor. The sensor was fabricated by simple dropping of the mixed solution of chitosan and PdAu nanoflowers on a glassy carbon electrode. Using electrochemical impedance spectroscopy and cyclic voltammetry, we characterized the modified electrode. The proposed sensor exhibited a good performance due to the excellent electrocatalytic activity of $\mathrm{PdAu}$ nanoflowers toward $\mathrm{H}_{2} \mathrm{O}_{2}$ in a wide linear range from 0.05 to $12 \mathrm{mM}$ with a low detection limit of $1.5 \mu \mathrm{M}(\mathrm{S} / \mathrm{N}=3)$. Moreover, the proposed sensor exhibited satisfying reproducibility and stability. The practical application of the nonenzymatic sensor was investigated via determination of $\mathrm{H}_{2} \mathrm{O}_{2}$ in real disinfected fetal bovine serum samples.
\end{abstract}

Keywords: PdAu nanoflowers; Electrocatalytical reduction; Hydrogen peroxide; Nonenzymatic sensor

\section{$\underline{\text { FULL TEXT }}$}

(C) 2019 The Authors. Published by ESG (www.electrochemsci.org). This article is an open access article distributed under the terms and conditions of the Creative Commons Attribution license (http://creativecommons.org/licenses/by/4.0/). 